\title{
ounisul simes
}

\section{DESIGN SISTÊMICO E INVENTÁRIO DO CICLO DE VIDA VISANDO UM APERFEIÇOAMENTO METODOLÓGICO \\ SYSTEMIC DESIGN AND LIFE CYCLE INVENTORY SEEKING A METHODOLOGICAL IMPROVEMENT}

Gabriel de Melo Senna ${ }^{1}$; João Vitor Souza Teixeira ${ }^{1}$; Larissa Arêdes Monteiro ${ }^{1}$; Adson Pinheiro Queiroz Viana²; Kátia Andréa Carvalhaes Pêgo²; Andréa Franco Pereira ${ }^{1}$.

${ }^{1}$ Programa de Pós-Graduação em Ambiente Construído e Patrimônio Sustentável - Universidade Federal de Minas Gerais.

${ }^{2}$ Programa de Pós-Graduação em Design - Universidade do Estado de Minas Gerais

\section{PALAVRAS CHAVE}

Design Sistêmico; Inventário do Ciclo de Vida; Avaliação do Ciclo de Vida; ACV; Biodigestor.

\section{KEY WORDS}

Systemic Design; Life Cycle Inventory; Life Cycle Assessment; LCA; Biodigester.

\section{RESUMO}

O presente estudo teve como objetivo a associação entre a metodologia do Design Sistêmico (DS) e o método de Avaliação do Ciclo de Vida (ACV) a fim de permitir a geração de resultados que possam contribuir para práticas eficientes de conservação ambiental. Foi realizado o Inventário do Ciclo de Vida de um sistema de biodigestão no contexto de uso extrativista do fruto da macaúba (Acrocomia aculeata) no território do Serro-MG. No sistema examinado, constatou-se que a implantação do biodigestor não se apresenta como opção sustentável, pois a quantidade de outputs gerados no território se mostra insuficiente para alimentá-lo, mantendo-o em sua capacidade máxima de funcionamento. Porém, a associação entre o DS e a ACV indica que uma análise articulada, envolvendo métodos qualitativos e quantitativos, com movimento contínuo de aproximação (zoomin) e de consideração do todo (zoom-out), pode auxiliar na estruturação de sistemas mais favoráveis à sustentabilidade.

\section{ABSTRACT}

This study aimed to associate the Systemic Design (SD) methodology and the Life Cycle Assessment (LCA) method in order to produce results that could contribute to efficient environmental conservation practices. The Life Cycle Inventory of a biodigestion system was carried out in the 
context of extractive use of the macauba fruit (Acrocomia aculeata) in the territory of Serro-MG. In the analyzed system, it has been found that the implantation of the biodigester is not presented as a sustainable option, as the amount of outputs generated in the territory is insufficient to feed it, keeping its maximum operating capacity. However, the association between SD and LCA indicates that an articulated analysis, involving qualitative and quantitative methods, with continuous movement of approximation (zoom-in) and consideration of the whole (zoom-out), can help to structuring systems in a favorable manner for sustainability.

\section{INTRODUÇÃO}

Este trabalho apresenta estudo sobre a análise da implantação de um sistema de biodigestão de resíduos no contexto de uso extrativista do fruto da macaúba (Acrocomia aculeata), palmeira perene encontrada no território do Serro, localizado em Minas Gerais.

O biodigestor a ser construído no distrito de São Gonçalo do Rio das Pedras (Serro-MG) integra um macrossistema desenvolvido sob a perspectiva do Design Sistêmico (DS), com vistas a criar atividades interconectadas em torno do extrativismo da macaúba. A perspectiva futura desse macrossistema é permitir a conservação do meio ambiente natural, gerando trabalho e renda para a comunidade local.

Sendo assim, o intuito deste estudo foi o de propor a associação entre a metodologia do DS e o método de Avaliação do Ciclo de Vida (ACV) - visto que ambos derivam do paradigma da complexidade sistêmica -, a fim de permitir a geração de resultados qualitativos e quantitativos que possam contribuir de maneira mais assertiva para práticas eficientes de conservação ambiental.

Desde os anos 1980, o pensamento linear, no âmbito da prática projetual - pensamento este que restringe o propósito à materialidade dos produtos e aos problemas técnicos específicos -, tem sido substituído pelo pensamento holístico que, uma vez mudando o enfoque dos objetos para os processos, facilita a percepção de relações que podem ser estabelecidas entre os diversos atores envolvidos (CESCHIN; GAZIULUSOY, 2019).

Por um lado, Bistagnino (2011) defende que, na abordagem tradicional e linear, os inputs (i.e. as entradas: matériasprimas/insumos) são inseridos em uma determinada atividade produtiva, gerando dois tipos de outputs (i.e. as saídas: produtos/resíduos): (i) o valorado - produto comercial e (ii) os desvalorizados - resíduos. $\mathrm{O}$ autor ressalta que, em um projeto desenvolvido por meio da abordagem holística, portanto, sistêmica, ambos os outputs têm valor: o artefato, que será comercializado e os refugos, que serão transformados em input para outras atividades produtivas, preferencialmente, no mesmo território. Nesse sentido, os outputs poderiam ser tanto negociados quanto doados.

Diante disto, Bistagnino (2011) propõe a metodologia do DS, que é estruturada no pensamento sistêmico (BERTALANFFY, 2012; CAPRA; LUISI, 2014). Esta visa o reestabelecimento do equilíbrio entre produção, ambiente e sociedade, fundamentado nos modi operandi dos sistemas biológicos da natureza. Sob este olhar, a meta não é solucionar um problema ou configurar um determinado produto, mas, sim, projetar relações, por meio de fluxos de matéria e energia entre os sistemas produtivos de determinado território, permitindo o 
estabelecimento e a visualização de um macrossistema.

Por outro lado, a ACV é um método, também sistêmico, que busca a quantificação dos impactos gerados pelos produtos, por meio do balanço do fluxo de inputs e outputs dos componentes do sistema (matéria-prima, produtos e serviços) e energia empregados, assim como dos resíduos gerados, em todas as etapas do seu ciclo de vida (PEREIRA, 2017).

Sendo assim, a associação entre DS e ACV para uma análise articulada, produzindo resultados qualitativos e quantitativos, apresenta promissor potencial.

Para tanto, a seguir, será apresentado o estudo conduzido sobre o Inventário de Ciclo de Vida (ICV), uma das etapas do método de $\mathrm{ACV}$, do biodigestor mencionado acima. Cabe ressaltar que este estudo, aqui revisado, foi publicado, originalmente, no IX Encontro de Sustentabilidade em Projeto (VIANA et al., 2021).

\subsection{Design Sistêmico (DS)}

$\mathrm{O}$ DS possui cinco linhas-guia (BISTAGNINO, 2011): a primeira delas (output-input) se refere à transformação, assim como ocorre na natureza, dos outputs (resíduos) de um sistema produtivo em input (recursos) para outro(s) sistema(s) - o que pode propiciar a emersão de novos postos de trabalho de qualidade e o aumento do fluxo econômico local. Como lembra Pauli (2010), na natureza, cada integrante realiza uma função e os descartes de um tornam-se recursos para outros numa dinâmica em cascata, na qual nada é desperdiçado. Assim, na natureza não existem desempregados e nem resíduos.

A segunda linha-guia (relações) evidencia que são as relações, tanto internas quanto externas, que geram o sistema em si, no qual todos os atores sociais têm importância e são estratégicos.

A terceira linha-guia (auto-geração) indica que os sistemas autopoiéticos se sustentam e se reproduzem autonomamente, definindo o próprio campo de ação e evoluindo em conjunto.

A quarta linha-guia (agir localmente) enfatiza a valorização dos recursos (materiais e imateriais) locais, assim como a solução dos problemas por meio da criação de novas oportunidades.

A quinta e última linha-guia (homem no centro do projeto) se refere ao ser humano relacionado ao próprio contexto ambiental, social, cultural e ético.

\subsection{Avaliação do Ciclo de Vida (ACV)}

$\mathrm{O}$ método de $\mathrm{ACV}$, definido pela Norma ISO 14040 (ABNT, 2009), tem como objetivo a avaliação dos impactos ambientais provocados pelos sistemas produtivos, com vistas a subsidiar o desenvolvimento ou melhoria de produtos e processos, o planejamento estratégico das empresas/organizações, bem como a definição de políticas públicas.

Para vencer a grande complexidade ligada ao levantamento dos dados quantitativos de entrada e saída, uma ACV pode ser realizada considerando limites no sistema, que pode ser completa, do berço ao túmulo (cradle-tograve), ou limitada, variando de berço ao portão de saída da fábrica (cradle-to-gate), dentro da fábrica entre portões de entrada e saída (gate-to-gate) ou do portão de entrada da fábrica ao túmulo (gate-to-grave). As etapas do método de ACV envolvem: (1) definição do objetivo e escopo; (2) análise do inventário; (3) avaliação dos impactos e (4) interpretação (ABNT, 2009). 


\subsection{Território do Serro}

O ICV do biodigestor aqui apresentado está diretamente relacionado à aplicação da metodologia do DS no território do Serro-MG, proposto por Pêgo (2016).

O território do Serro-MG faz parte da Estrada Real, importante rota turística do Estado de Minas Gerais. Além da cidade, propriamente dita, do Serro, estão incluídos no território os distritos de Boa Vista de Lages, Capivari, Galheiros, Pedra Redonda e São Gonçalo do Rio das Pedras.

Dentre as diversas atividades produtivas abordadas por Pêgo (2016), destaca-se a manufatura de cosméticos, realizada por mulheres artesãs da comunidade de São Gonçalo do Rio das Pedras. Estes cosméticos são produzidos a partir de frutos do cerrado encontrados na região tais como a macaúba, a amescla, a mutamba e o pacari. Tal produção envolve processos, desde a coleta extrativista das plantas nativas até o beneficiamento dos frutos, por meio de técnicas transmitidas por várias gerações.

Após a compreensão quanto aos sistemas produtivos existentes no território do SerroMG, Pêgo (2016) investigou as qualidades intrínsecas de cada elemento da macaubeira, a fim de verificar quais atividades produtivas locais ligadas ao extrativismo da macaúba poderiam incorporar outputs como inputs. A pesquisa avaliou os diversos subsistemas, a fim de revelar os potenciais, tanto dos pontos positivos quanto dos negativos, estes últimos considerados no DS como "alavancas para mudança". Estas análises constituíram o alicerce sobre o qual o macrossistema foi projetado.

Sendo assim, no estudo ora apresentado, será tratado apenas o sistema da macaúba e, especificamente, o subsistema do biodigestor de matéria orgânica.

\section{MATERIAIS E MÉTODOS}

A partir do macrossistema proposto por Pêgo (2016), de produção de cosméticos a partir do extrativismo de frutos de palmeiras de macaúba, no território do Serro-MG, definiuse o subsistema do biodigestor como objeto de análise, limitando-se ao Inventário de Ciclo de Vida (ICV).

Para a realização do ICV, foram definidos os objetivos e escopo do estudo. Como referência, foram coletadas informações sobre a manufatura e o funcionamento de um biodigestor de modelo canadense, selecionado, principalmente, em razão de seu baixo custo. $\mathrm{O}$ espaço geográfico foi delimitado ao município do Serro-MG e aos distritos envolvidos, com destaque a São Gonçalo do Rio das Pedras onde se situa a produção de cosméticos. Foi definida como Unidade Funcional a colheita de frutos de 10 macaubeiras por mês. Todos os dados apresentados têm origem em fontes secundárias, estimativas e revisões bibliográficas, tendo em vista a impossibilidade de obtenção de dados primários, já que o biodigestor ainda não foi implantado.

Os dados de entrada dizem respeito aos resíduos vegetais (denominadas "tortas" de macaúba), aos resíduos animais (dejetos de bovinos, suínos e aves da região) e à água pluvial (que envolve a captação, o dimensionamento do sistema e a instalação hidráulica). Também foram considerados os custos e impactos dos insumos para sua construção. Os dados de saída do sistema dizem respeito à produção de biogás e de fertilizante. 


\subsection{O subsistema biodigestor}

No biodigestor, a produção de biogás e de fertilizante implica no consumo e liberação de matéria e energia. Sendo assim, uma avaliação holística do desempenho ambiental do biodigestor é mais apropriada, pois facilita a identificação dos pontos a serem aprimorados. Para tanto, na Figura 1, os dados qualitativos do subsistema foram sistematizados, servindo de suporte legível e permitindo a continuidade das análises e discussões em termos quantitativos.

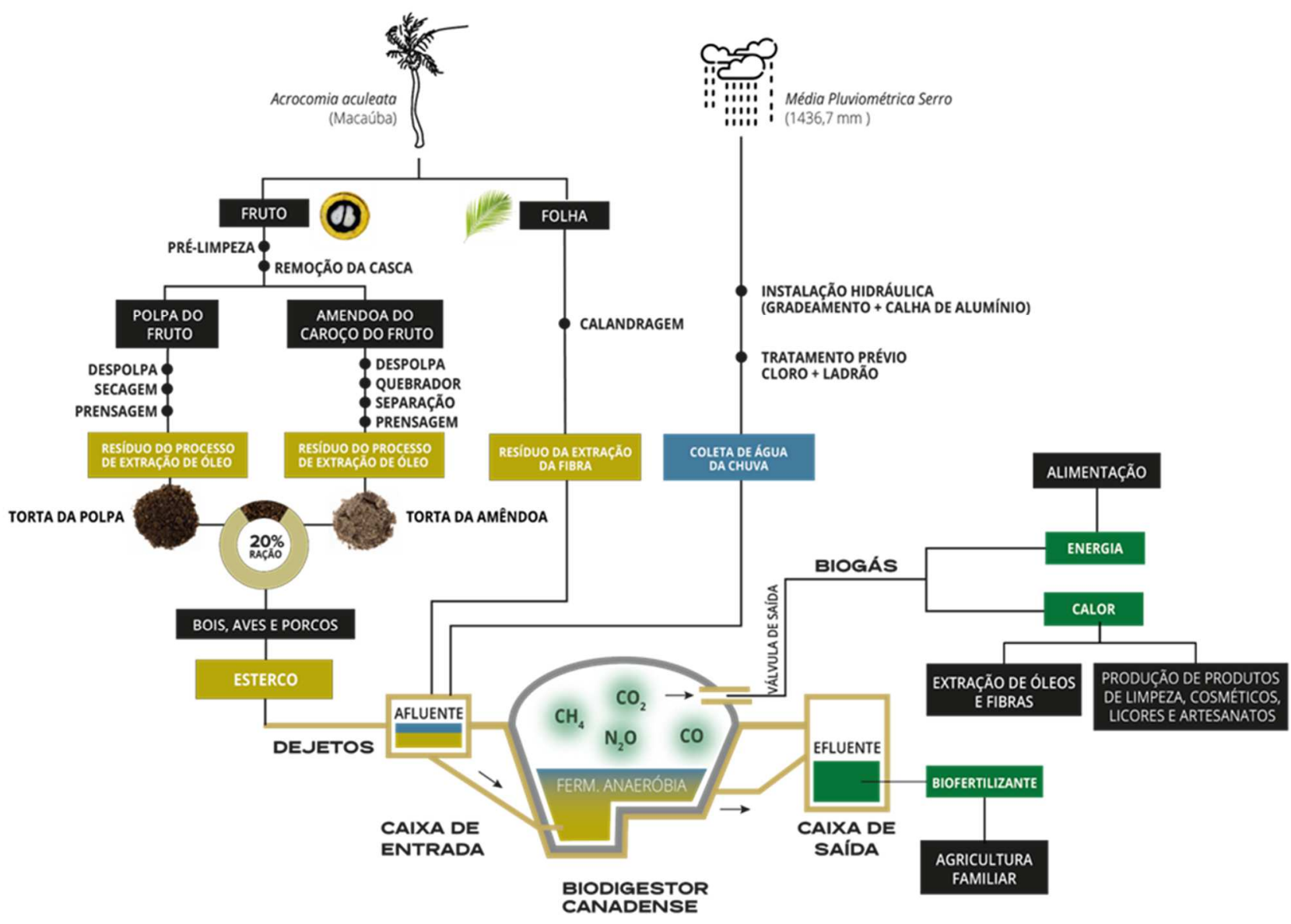

Figura 1. Fluxograma qualitativo do subsistema biodigestor. Fonte: elaborado pelos autores.

O propósito foi analisar a viabilidade da instalação in loco de um biodigestor de modelo canadense de baixo custo, com capacidade para $16 \mathrm{~m}^{3}$, considerando, principalmente, a matéria-prima local advinda dos resíduos vegetais (tortas) da macaúba e do esterco animal. A quantidade de $\mathrm{CO}_{2}$ foi a referência mensurável à qual os dados de entrada e saída foram ponderados.

\subsubsection{Resíduos vegetais}

No subsistema, as tortas de macaúba, representadas na Figura 2, são resíduos consideráveis no processo de extração do óleo de duas partes do fruto: o mesocarpo (polpa) e o endocarpo (amêndoa). 
Pêgo (2016) propõe que as tortas (output) sejam convertidas em insumos na alimentação

ruminantes (até 20\%) por ser aprazível e boa fonte de energia para os animais (IICA, 2009;

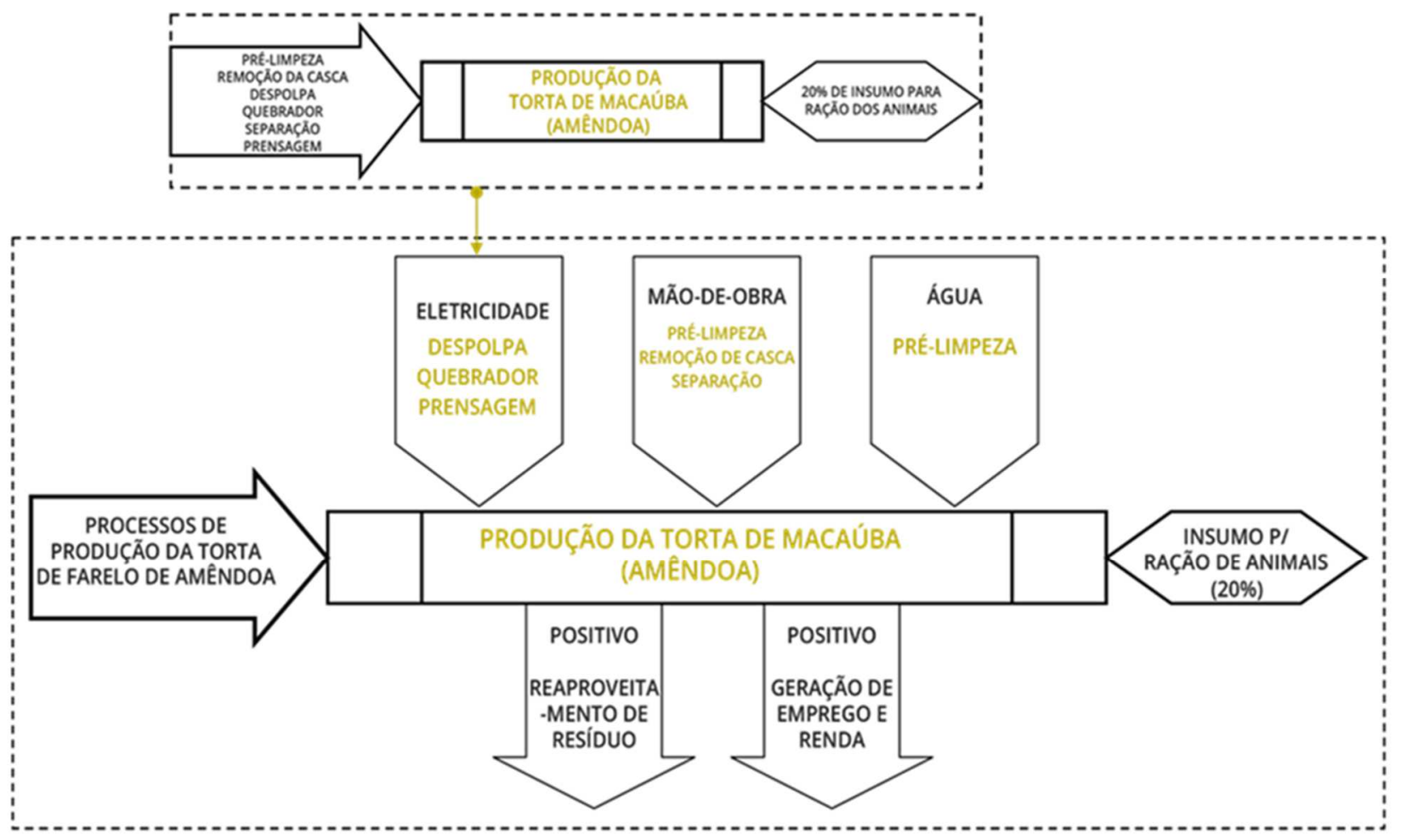

Figura 2. Processo de produção da torta de macaúba. Fonte: elaborado pelos autores.

animal devido a dois aspectos: a) as despesas com o manejo nutricional de animais para a criação intensiva, gerando um alto custo de produção pecuária (LOPES; FERREIRA, 2017) e b) a utilização da torta do mesocarpo e endocarpo na formulação de dietas para

\subsubsection{Resíduos animais}

Para a alimentação do biodigestor, os dejetos de animais (bovinos, suínos e aves), representam $80 \%$ do input no subsistema. A preparação desse insumo, antes de alimentar o biodigestor, consiste no processo de compostagem térmica, no qual a matéria seca é submetida à fermentação aeróbia, com a introdução de oxigênio e calor, para a retirada de patógenos presentes na matéria (Figura 3). Após o processo, o esterco se torna uma matéria orgânica mais estável, com a liberação de água e nutrientes. Não obstante, cabe
RIGUEIRA et al., 2017).

Além disto, é possível agregar $10 \%$ dos resíduos vegetais (fruto ou folha) a $90 \%$ dos dejetos animais no processo de digestão anaeróbia para a produção de biogás.

destacar que o processo de fermentação aeróbia libera o dióxido de carbono $\left(\mathrm{CO}_{2}\right)$, um dos principais gases de efeito estufa (GEE).

\subsubsection{Captação de água pluvial}

a) Dimensionamento do sistema

Um dos insumos que pode ser aproveitado no biodigestor é a água de chuva, por meio de um sistema de captação interligado. A partir das instalações hidrosanitárias, a água não utilizada para fins nobres, tais como higiene e dessedentação, pode ser aproveitada no 


\section{¿unisul sim}

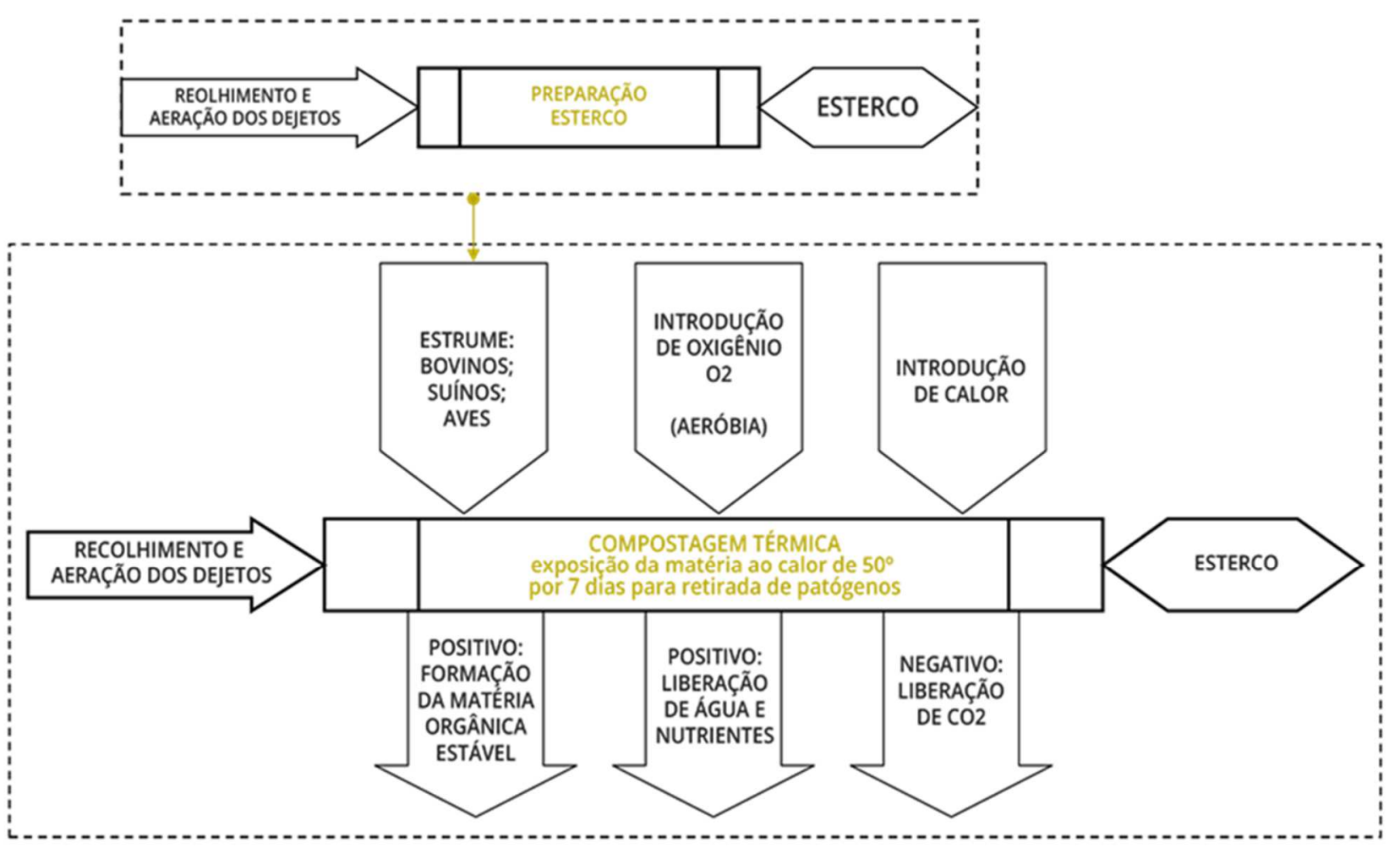

Figura 3. Processo de compostagem para produção de esterco. Fonte: elaborado pelos autores.

sistema de biodigestão para diluir o efluente orgânico e facilitar seu transporte (FIEMG, 2016).

No Brasil, a Norma que define as diretrizes para captação de água pluvial é a ABNT NBR 10.844 (1989). Esta norma foi utilizada para o dimensionamento do sistema proposto no estudo. Para tanto, foi necessário, primeiramente, estimar a demanda de água pluvial, tendo em vista que a capacidade de armazenamento do sistema precisa ser respeitada, evitando super ou subdimensionamento, o que poderia acarretar prejuízos ao sistema.

No cenário proposto, em que a capacidade máxima de armazenamento do biodigestor é de $16 \mathrm{~m}^{3}$, estimou-se um volume de $20 \%$ do total disponível para a parte líquida do sistema. Assim, considerou-se que $3,2 \mathrm{~m}^{3}$ se referem à capacidade de armazenamento de água pluvial.
Num segundo momento, foi necessário verificar o índice pluviométrico da região, pois este é fundamental para presumir a disponibilidade de água pluvial para captação (FIEMG, 2016). Sendo assim, utilizou-se um estudo da EMBRAPA (2010), que acompanhou a pluviometria de todas as cidades de Minas Gerais. Os resultados para o Serro são apresentados na Figura 4.

Para o cálculo de escoamento, o método Ripple é o mais utilizado. Entretanto, ainda se fez necessário multiplicar os valores pelo coeficiente de runoff (ou coeficiente de escoamento). Nesta perspectiva, é possível extrair a quantidade de água que irá escorrer para dentro do sistema, em função do material em que a superfície de captação foi construída. Este material ainda apresenta um panorama da qualidade da água captada, pois, dependendo do material, o mesmo irá interagir com a água 


\section{GESTÃO \& SUSTENTABILIDADE AMBIENTAL

podendo adicionar impurezas à mesma (FIEMG, 2016).

Neste contexto, é possível ainda constatar o perfil do reservatório ao longo do ano, ou seja, se ele estará extravasando ou esvaziando. Essa informação é obtida com a subtração da demanda de água pela quantidade captada. No caso do reservatório em questão, ele estará sempre esvaziando, uma vez que a capacidade de retenção é maior do que o volume de chuva disponível. O Quadro 1 apresenta um panorama geral dos resultados.

\section{sunisul}

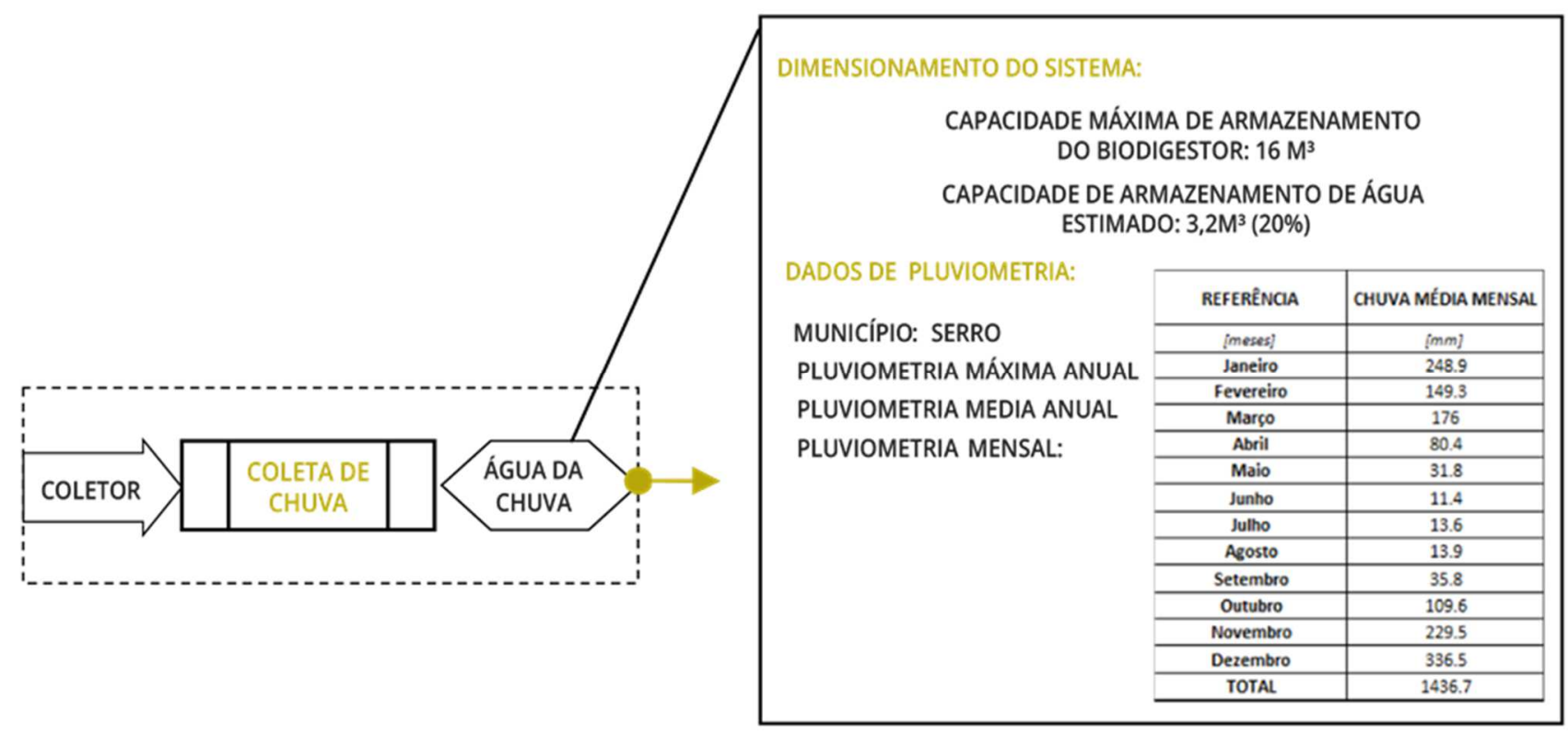

Figura 4. Dados pluviométricos da cidade de Serro-MG em mm. Fonte: EMBRAPA, 2010, p.86

\begin{tabular}{|c|c|c|c|c|c|c|}
\hline TIPO DE ESTRUTURA: & Cimento & ÁREA DO SISTEMA: & {$\left[m^{2}\right]$} & MUNICípIO: & Serro & \begin{tabular}{l|l} 
CR MÉDIO: & 0.85 \\
\end{tabular} \\
\hline REFERÊNCIA & CHUVA MÉDIA MENSAL & DEMANDA MENSAL & $\begin{array}{l}\text { VOLUME DE CHUVA } \\
\text { MENSAL }\end{array}$ & BALANÇO DE VOLUME & \multirow{2}{*}{$\begin{array}{l}\text { SITUAÇ̃̃O DO } \\
\text { RESERVATÓRIO }\end{array}$} & $\begin{array}{l}\text { CÁLCULO DO VOLUME DO } \\
\text { RESERVATÓRIO }\end{array}$ \\
\hline [meses] & {$[\mathrm{mm}]$} & {$\left[m^{\prime}\right]$} & {$\left[m^{2}\right]$} & {$\left[m^{2}\right]$} & & {$\left[m^{2}\right]$} \\
\hline Janeiro & 248.9 & 3.20 & 1 & 2 & Esvaziando & 3.20 \\
\hline Fevereiro & 149.3 & 3.20 & 1 & 2 & Esvoziondo & 3.20 \\
\hline Março & 176 & 3.20 & 1 & 2 & Esvoziondo & 3.20 \\
\hline Abril & 80.4 & 3.20 & 0 & 3 & Esvaziondo & 3.20 \\
\hline Maio & 31.8 & 3.20 & 0 & 3 & Esvoziondo & 3.20 \\
\hline Junho & 11.4 & 3.20 & 0 & 3 & Esvoziondo & 3.20 \\
\hline Julho & 13.6 & 3.20 & 0 & 3 & Esvoziondo & 3.20 \\
\hline Agosto & 13.9 & 3.20 & 0 & 3 & Esvaziondo & 3.20 \\
\hline Setembro & 35.8 & 3.20 & 0 & 3 & Esvoziondo & 3.20 \\
\hline Outubro & 109.6 & 3.20 & 1 & 3 & Esvaziondo & 3.20 \\
\hline Novembro & 229.5 & 3.20 & 1 & 2 & Esvoziondo & 3.20 \\
\hline Dezembro & 336.5 & 3.20 & 2 & 1 & Esvaziondo & 3.20 \\
\hline TOTAL & 1436.7 & 38.4 & 7 & 31 & & 12 \\
\hline
\end{tabular}

Quadro 1. Resultados do dimensionamento do sistema de captação de água pluvial.

Fonte: elaborado pelos autores

Revista Gestão e Sustentabilidade Ambiental., v. 10, n. esp, p. 119-133, jul. 2021. 
b) Instalação hidráulica

Além de mensurar o sistema de captação de água, foi necessário, ainda, dimensionar as calhas e canos que irão compor o sistema de captação. Para tanto, foi utilizada a Norma ABNT supracitada que, por sua vez, emprega o método de Manning para o cálculo. Neste caso, a variável mais importante é a vazão (Figura 5), que irá determinar todas as outras características da instalação hidráulica. Para determiná-la, utilizou-se a fórmula de Manning $(\mathrm{Qc}=\mathrm{K} * \mathrm{~S} / \mathrm{n} * \mathrm{RH} 2 / 3 * \mathrm{i} 1 / 2)$, sendo:

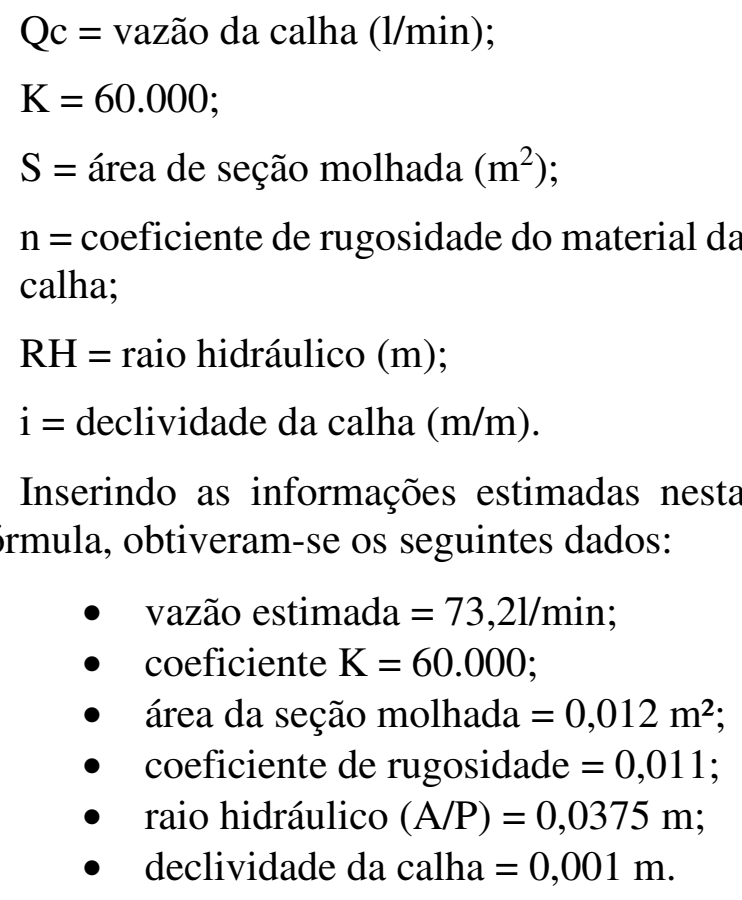

Estes dados podem auxiliar na aquisição e instalação das calhas e/ou tubos. Para o sistema em questão, foi selecionada uma calha aberta e retangular.

c) Outros insumos
Por fim, foi necessário identificar outros insumos importantes para o bom funcionamento do biodigestor, que serão considerados no momento de calcular os impactos do Ciclo de Vida do sistema como um todo. Após a aquisição, todos os insumos deverão ser transportados até a localidade, o que irá impactar em fatores tais como emissão de $\mathrm{CO}_{2}$, consumo de combustível (diesel) e outros relacionados ao transporte. Para se quantificar cada um destes insumos (gradeamento, calhas, agente desinfetante, hidrômetro, ladrão de escoamento, solenóide) seria necessário um estudo mais aprofundado do sistema e tentativas práticas com monitoramento contínuo de uso, para adequação das doses e quantidades.

\subsubsection{Custos e impactos dos insumos para construção do biodigestor.}

Neste estudo, dentre os modelos de biodigestor identificados a partir de revisão bibliográfica (CALZA et al., 2015), o canadense (Figura 6) foi definido como referência, devido ao seu baixo custo e facilidade de execução.

O biodigestor canadense é configurado, basicamente, por uma caixa de alvenaria enterrada abaixo do nível do solo (onde ocorre a retenção da biomassa), recoberta por uma lona atirantada e um sistema de tubulações para coleta do biogás.

Os componentes básicos para a sua construção são: (i) blocos de concreto; (ii) cimento; (iii) geomembrana de PVC; (iv) tubos de PVC; (v) lona impermeável de PVC. 


\section{sunisul}

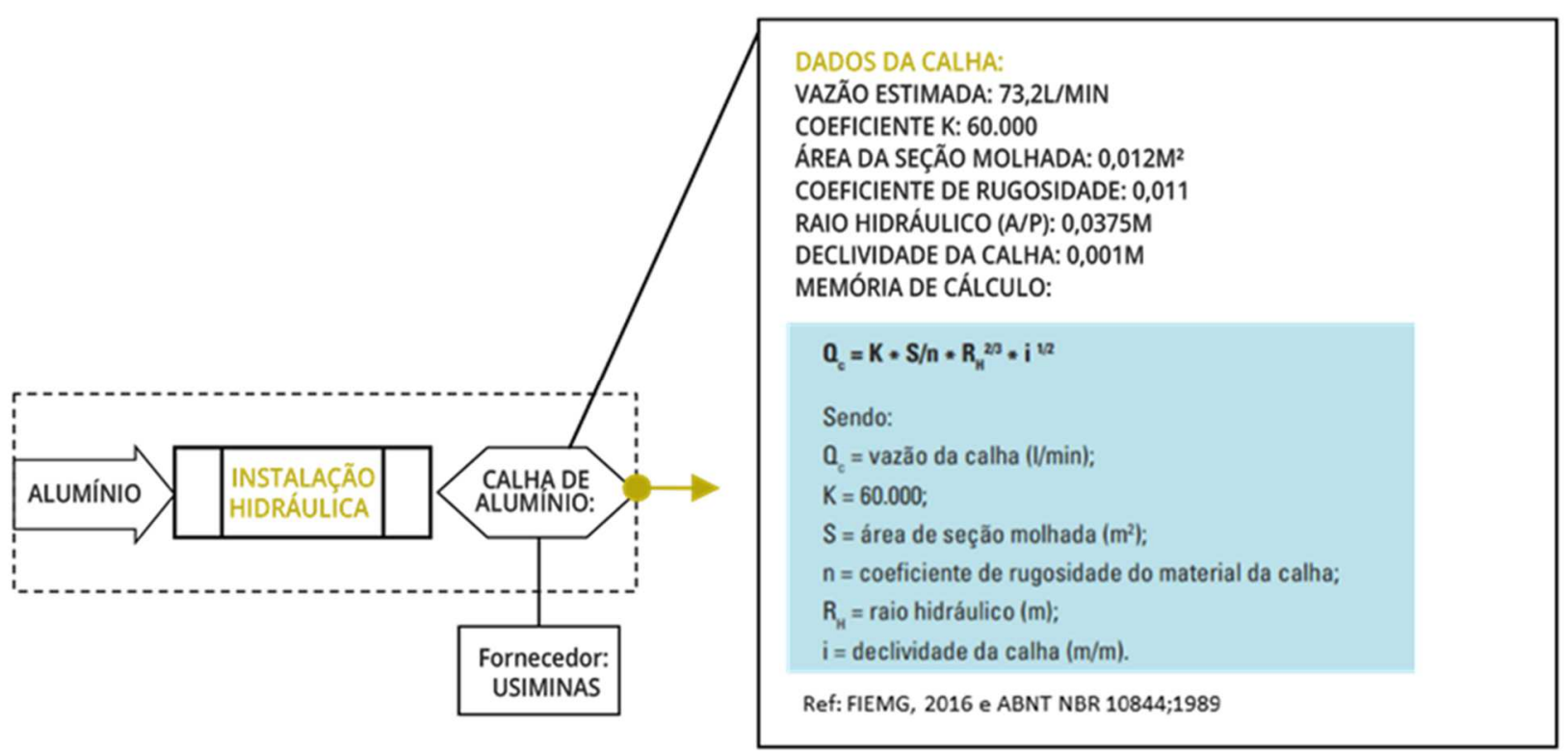

Figura 5. Processo de instalação hidráulica e equação. Fonte: ABNT, 1989 apud FIEMG, 2016.

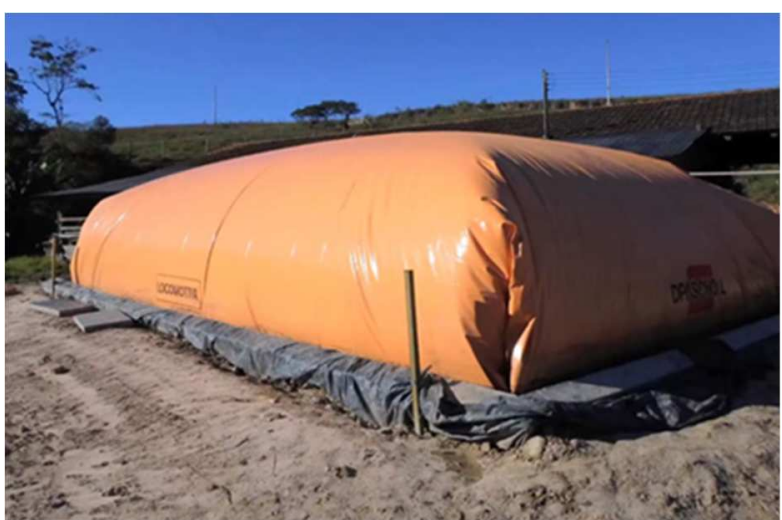

Figura 6. Biodigestor modelo canadense.

Fonte: EPAGRI, 2021.

A construção desse biodigestor é relativamente simples, podendo ser realizada por um grupo de três a seis pessoas da própria comunidade, desde que assessorados por um profissional especializado. Os materiais especificados (Figura 7) são facilmente encontrados em depósitos de construção, acessados no próprio município.

Destaca-se que o maior consumo de energia na produção deste tipo de biodigestor se encontra nas peças de PVC (geomembrana, sistema de tubulações e lona), em razão do seu processo de fabricação, como demonstrado na Tabela 1. Embora o concreto apresente maior consumo por unidade funcional, o PVC apresenta maior consumo absoluto, sendo, portanto, um ponto a ser reavaliado, a fim de aprimorar o processo construtivo do biodigestor (do tipo canadense), com vistas a diminuir os impactos ambientais.

\subsection{Produção do biogás no Brasil e no Serro}

De acordo com o último levantamento do SEBRAE (2020), de todo o biogás produzido em território nacional, $9,7 \%$ provém da pecuária. A maior produção de biogás no Brasil, de fontes pecuárias, está no Estado de Minas Gerais, seguido pelo Paraná e Mato Grosso (Gráfico 1). Por meio do levantamento de dados do SEBRAE (2020), foi possível verificar a produção do biogás no território do Serro-MG. Atualmente, no município, a produção anual do biogás é de $369.900 \mathrm{Nm}^{3}$ ou $3,699 \times 10^{-21} \mathrm{~m}^{3}$. Ainda de acordo com este levantamento, toda a produção de biogás tem origem em dejetos de bovinos, sendo nula a geração de biogás a partir de dejetos de aves e suínos. 

AMBIENTAL

\section{¿unisul sim}

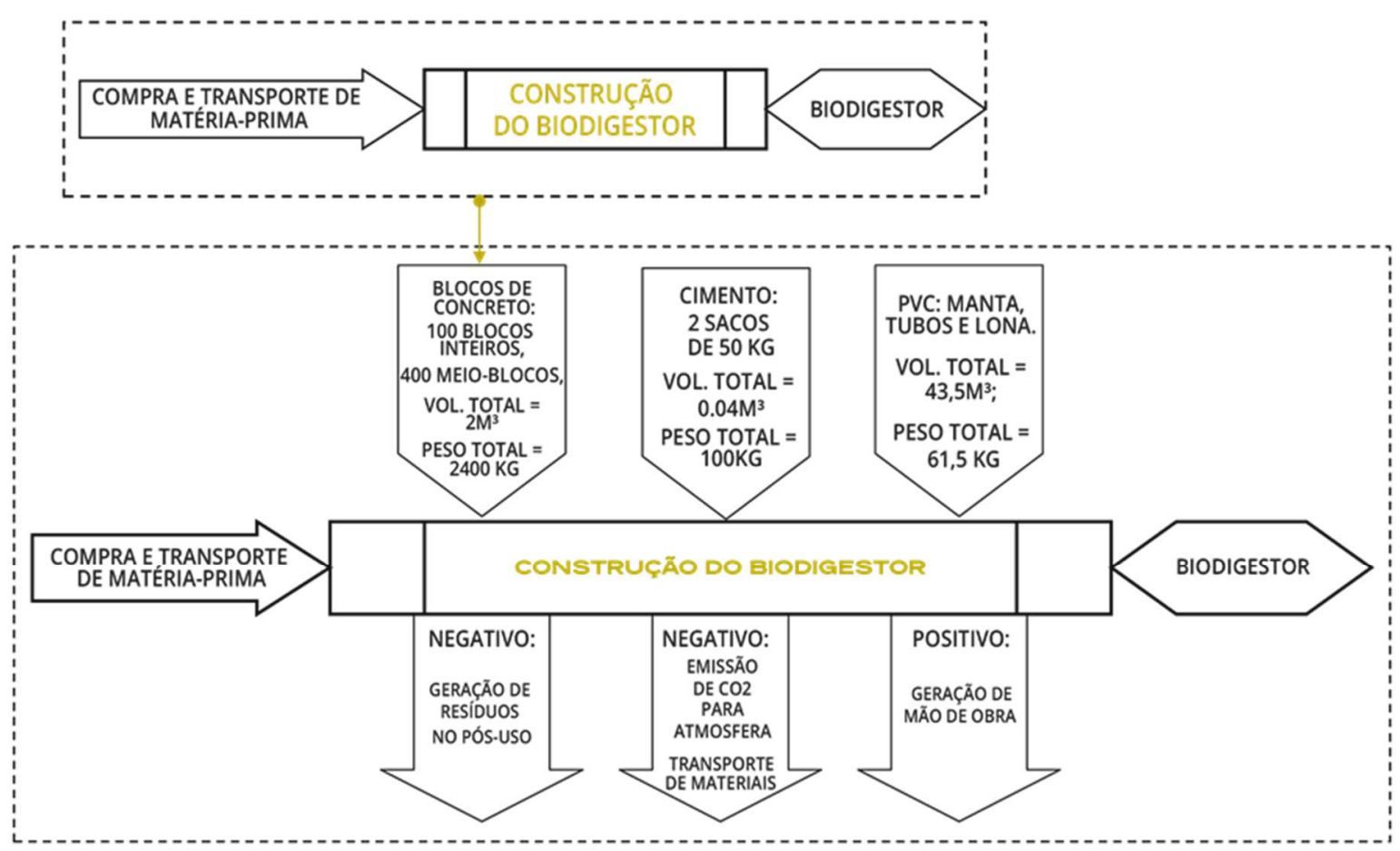

Figura 7. Processo de construção do biodigestor. Fonte: elaborado pelos autores

\begin{tabular}{|c|c|c|c|}
\hline Componente de entrada & Coeficiente energético & Unidades & Vida Ûtil \\
\hline Mão-de-obra & 4,39 & MJ homem ${ }^{-1} \mathbf{h}^{-1}$ & - \\
\hline Óleo diesel & 47.48 & $\mathrm{MJ} \mathrm{L}^{-1}$ & - \\
\hline Graxa & 43,38 & $\mathrm{MJ} \mathrm{kg} \mathbf{~}^{-1}$ & - \\
\hline Óleo lubrificante & 37.75 & $\mathrm{MJ} \mathrm{L}^{-1}$ & - \\
\hline Chapas de aşo & 62.78 & $\mathrm{MJ} \mathrm{kg}^{-1}$ & 20 anos \\
\hline Geomembrana flexive1 PVC $(1.000 \mathrm{~m} \mu)$ & 119.99 & $\mathrm{MJ} \mathrm{kg}^{-1}$ & OS anos ${ }^{6}$ \\
\hline Lona de impermeabilizaşăo PVC ( $(\$ 00 \mathrm{m \mu})$ & 119.99 & $\mathrm{MJ} \mathrm{kg}$ & $05 \operatorname{anos}^{6}$ \\
\hline Parafusos de ą̧o & 62.78 & $\mathbf{M J ~ k g} \mathbf{~ g}^{-1}$ & 20 anos \\
\hline PVC (Tubulaşão $100 \mathrm{~mm}$ ) & 119.99 & MJ kg-1 & 40 anos \\
\hline PVC (Tubulaşão $200 \mathrm{~mm}$ ) & 119.99 & $\mathrm{MJ} \mathrm{kg}^{-1}$ & 40 anos \\
\hline Polietileno (Caixa difusora de fluxo) & 108.7 & MJ kg $\mathbf{~ g}^{-1}$ & So anos \\
\hline Fundaşâo/Concreto & 641.64 & $\mathrm{MJ} \mathrm{m}^{-3}$ & - \\
\hline Caminbão Volkswagen VW 11130 & 57,2 & $\mathrm{MJ} \mathrm{kg}^{-1}$ & 10.000 horas \\
\hline Retroescavadora Caterpillar $430 \mathrm{E} \mathrm{IT}$ & 57.2 & $\mathrm{MJ} \mathrm{kg}^{-1}$ & 10.000 horas \\
\hline
\end{tabular}

Tabela 1. Componentes construtivos do biodigestor canadense. Fonte: Veloso et al., 2018.

Revista Gestão e Sustentabilidade Ambiental., v. 10, n. esp, p. 119-133, jul. 2021. 


\section{sunisul}

\subsection{Energia e calor}

$\mathrm{Na}$ falta de dados relativos à quantidade exata de animais existentes no Serro, a análise das eventuais produções de energia e calor teve como ponto de partida a capacidade máxima de produção de biogás a cada ciclo do modelo de biodigestor adotado.

Gráfico 1: Produção de Biogás com fonte pecuária, por Estado brasileiro. Fonte: SEBRAE, 2020

Segundo o SEBRAE (2021), $1 \mathrm{~m}^{3}$ de biogás equivale a 0,69 litros de óleo diesel, ou a 0,53 $\mathrm{kg}$ de gás liquefeito de petróleo ou ainda, a 2,07 kWh de energia elétrica. Aplicados ao biodigestor proposto, e considerando seu funcionamento na capacidade máxima de 16 $\mathrm{m}^{3}$, a cada ciclo de trabalho do equipamento, será obtido o equivalente a 11,04 litros de óleo diesel ou $8,48 \mathrm{~kg}$ de gás liquefeito de petróleo ou 33,12 kWh de energia elétrica.

\section{ICV DO BIODIGESTOR}

A Figura 8 mostra o modelo de representação gráfica do Inventário de Ciclo de Vida do biodigestor analisado neste estudo.

Neste modelo, é possível observar os processos considerados na análise, quais sejam: torta de macaúba como alimento para animais, água pluvial, construção do biodigestor, preparação do esterco, deposição de rejeitos no biodigestor, biodigestão e obtenção de energia, calor e fertilizante, que retroalimentam as diversas atividades produtivas locais, fechando, assim, o ciclo.

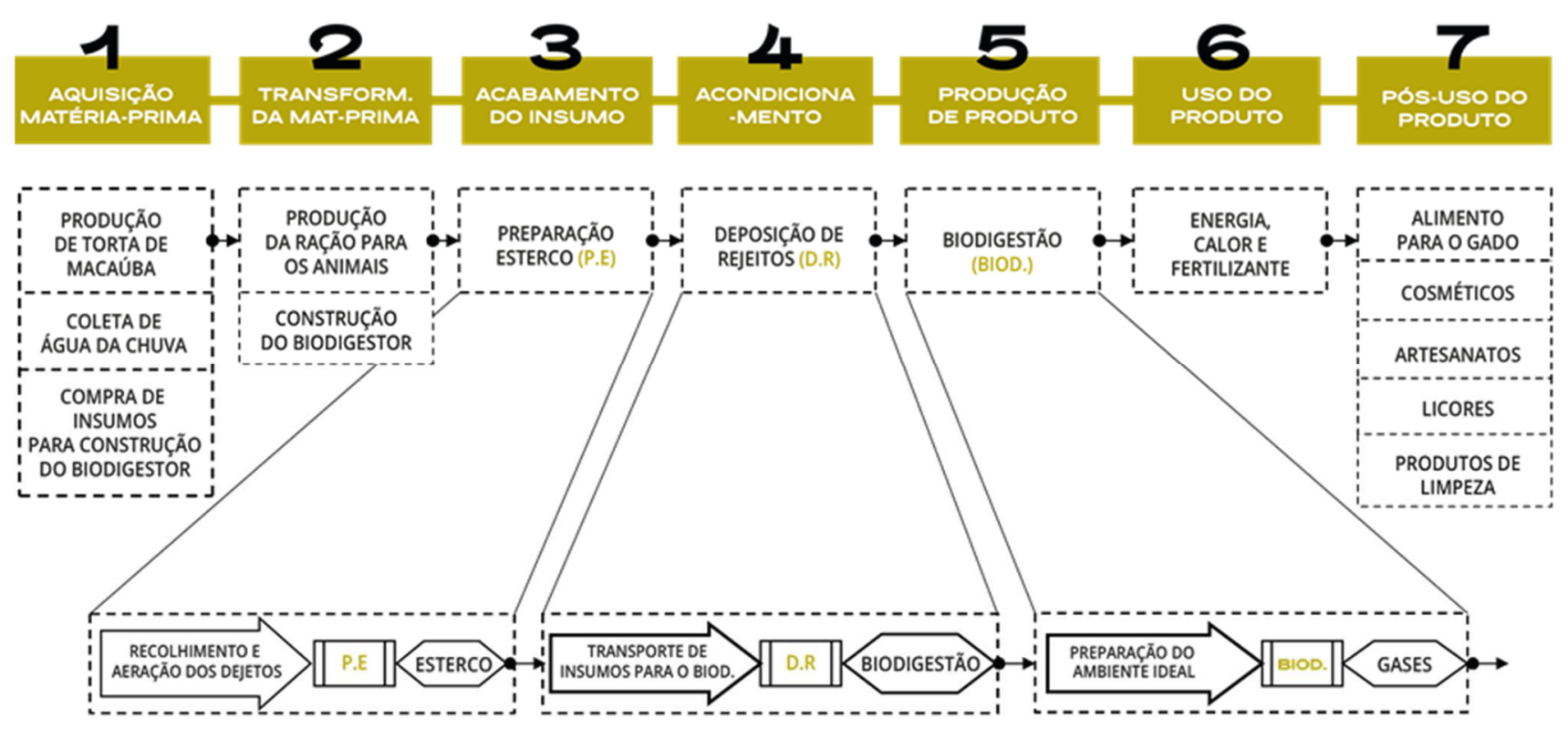

Figura 8. Inventário do Ciclo de Vida do subsistema biodigestor. Fonte: elaborado pelos autores.

\section{CONCLUSÕES}

O objetivo do presente estudo foi o de experimentar a associação entre a metodologia do Design Sistêmico (DS) e o método de
Avaliação do Ciclo de Vida (ACV), com vistas a obter resultados que possam contribuir de maneira mais assertiva para práticas eficientes de conservação ambiental. 
Nesse sentido, foi possível concluir sobre as vantagens que a associação dos métodos DS e ACV pode trazer, estando relacionada ao olhar articulado sobre a discussão qualitativa e quantitativa da questão, bem como ao movimento contínuo de aproximação (zoomin), antecipação e observação do todo (zoomout). Este movimento, que revela as associações possíveis, facilita o processo das necessárias mudanças de abordagens, de adoção de técnicas, estratégias e atitudes frente aos desafios contemporâneos.

O Design Sistêmico se destaca como uma metodologia mais apropriada para o enfrentamento das crises atuais, pois instiga a transição da abordagem linear para a holística, inclusive, no âmbito projetual. Já a Avaliação do Ciclo de Vida se configura como um método capaz de otimizar o desempenho ambiental dos produtos, processos e serviços, auxiliando nas tomadas de decisão.

O caso aqui analisado diz respeito a um subsistema de biodigestão de resíduos a ser implantado no distrito de São Gonçalo do Rio das Pedras (Serro-MG), integrando um macrossistema desenvolvido sob a perspectiva do DS, que visou propor atividades interconectadas em torno do extrativismo da macaúba.

Assim, a partir da elaboração do Inventário do Ciclo de Vida do biodigestor e dos dados levantados sobre o território do Serro-MG, observou-se que, em principio, sua implantação não representa uma opção sustentável, pois a quantidade de ouputs gerados no território é insuficiente para alimentá-lo, mantendo-o em funcionamento em sua capacidade máxima.

Não obstante, vários benefícios podem ser vislumbrados com a implantação local de um biodigestor: produção de biogás (energia

\section{¿Unisul उime}

limpa, local e de baixo custo) e fertilizante (local e livre de contaminantes); geração de trabalho e renda na comunidade (a partir da coleta dos resíduos orgânicos e manutenção do biodigestor); promoção da educação ambiental (envolvendo os alunos das escolas municipais); entre outros. Observa-se, no entanto, que o alcance do sucesso depende do envolvimento de toda a comunidade, esforçando-se em conjunto para manter o sistema saudável e equilibrado.

Sendo assim, a associação entre DS e ACV pode contribuir, de um lado, para a observação e questionamento das limitações que por ventura se apresentem, de outro, para visualizar perspectivas futuras, subsidiando propostas que possam sobrepujar tais limitações e as encarando como "alavancas para mudança".

\section{REFERÊNCIAS}

ASSOCIAÇÃO BRASILEIRA DE NORMAS TÉCNICAS - ABNT. NBR ISO 10844: instalações prediais de águas pluviais. Rio de Janeiro, 1989. 13 p.

ASSOCIAÇÃO BRASILEIRA DE NORMAS TÉCNICAS - ABNT. NBR ISO 14040: gestão ambiental: avaliação do ciclo de vida: princípios e estrutura. Rio de Janeiro, 2009. 10 p.

BERTALANFFY, L. V. Teoria geral dos sistemas: fundamentos, desenvolvimento e aplicações. Petrópolis: Vozes, 2012. 360 p.

BISTAGNINO, L. Design sistemico: progettare la sostenibilità produttiva e ambientale. Bra: Slow Food, 2011. 310 p.

BRASIL. Ministério do Meio Ambiente. Dispõe sobre a classificação dos corpos de água e diretrizes ambientais para o seu enquadramento, bem como estabelece as 
condições e padrões de lançamento de efluentes, e dá outras providências. [Brasília]: CONAMA; Ministério do Meio Ambiente, 2005. 27 p.

CALZA, L.; LIMA, C.; NOGUEIRA, C.; SIQUEIRA, J.; SANTOS, R. Avaliação dos custos de implantação de biodigestores e da energia produzida pelo biogás. Engenharia Agrícola, Jaboticabal, v.35, n.6, p.990-997, nov./dez. 2015. ISSN: 1809-4430.

CAPRA, F; LUISI, P. L. A visão sistêmica da vida: uma concepção unificada e suas implicações filosóficas, políticas, sociais e econômicas. São Paulo: Cultrix, 2014. 615 p.

CESHIN, F.; GAZIULUSOY, I. Design for sustainability: a multi-level framework from products to socio-technical systems. London: Routledge, 2019. 186 p.

EMPRESA BRASILEIRA DE PESQUISA AGROPECUÁRIA - EMBRAPA. Índices Pluviométricos de Minas Gerais. Boletim de Pesquisa e Desenvolvimento. N. 30. dez $2010 . \quad$ Disponível em: https://www.embrapa.br/agua-naagricultura/previsao-de-clima-echuva-nobrasil. Acesso em: 21 fev. 2021.

EMPRESA DE PESQUISA AGROPECUÁRIA E EXTENSÃO RURAL DE SANTA CATARINA - EPAGRI. Biodigestor. Youtube, 26 set. 2016. Disponível em: https://www.youtube.com/watch?v=pjAvfzcw js8. Acesso em 10 fev. 2021.

FEDERAÇÃO DAS INDÚSTRIAS DE MINAS GERAIS - FIEMG. Aproveitamento de Água Pluvial. [2016]. Disponível em: https://www7.fiemg.com.br/Cms_Data/Conte nts/central/Media/Documentos/Biblioteca/PD Fs/SDI/2016/RecursosHidricos/SS-0115-15CARTILHA-AGUA-DA-

CHUVAINTRANET.pdf. Acesso em: $21 \mathrm{fev.}$ 2021.
INSTITUTO INTERAMERICANO DE COOPERAÇÃO PARA A AGRICULTURA IICA. Biocombustível em foco. Boletim Informativo. Novembro, 2009 - Ano I / No 11. Disponível em: http://www.iica.org.br. Acesso em 10 fev. 2021.

LOPES, F. B.; FERREIRA, J. L. Sensibilidade econômica do sistema intensivo e semiintensivo da produção em caprinos leiteiros: benefícios dos fatores tangíveis e intangíveis. Revista Acadêmica: Ciência Animal, v. 11, n. 4, p. 403-411, 2017. ISSN 1981-4178.

PAULI, G. Blue economy: nuovo rapporto al club di Roma - 10 anni, 100 innovazioni, 100 milioni di posti di lavoro. Milano: Edizioni Ambiente, 2010. 342 p.

PÊGO, K. A. C. Approach of the systemic design in material and intangible culture of Estrada Real: territorial Serro case. 2016. 204 f. Thesis $(\mathrm{PhD})$ - Politecnico di Torino, Torino, Italy, 2016.

PEREIRA, A. F. ACV para designers e arquitetos: experiências de modelamento do inventário do ciclo de vida. In: OLIVEIRA, A. J.; FRANZATO, C.; DEL GALDIO, C. (Org.). Ecovisões projetuais: pesquisas em design e sustent abilidade no Brasil. São Paulo: Blucher, 2017. cap. 18, p. 219-234.

RIGUEIRA, J. P. S.; MONÇÃO, F. P.; SALES, E. C. J.; REIS, S. T.; ALVES, D. D.; AGUIAR, A. C. R.; ROCHA JÚNIOR, V. R.; CHAMONE, J. A. Composição química e digestibilidade in vitro de tortas da macaúba. Revista UNIMONTES científica, Montes Claros, v. 19, n. 2, p. 197-216, jul./dez. 2017.

SERVIÇO BRASILEIRO DE APOIO ÀS MICRO PEQUENAS EMPRESAS SEBRAE. Data Sebrae Biogás. [S.I.], 20162021. Disponível em: https://datasebrae.com.br/biogas/. Acesso em: 18 fev. 2021. 
$\begin{array}{lll}\text { SERVIÇO } & \text { BRASILEIRO } & \text { DE APOIO ÀS } \\ \text { MICRO } & \text { PEQUENAS } & \text { EMPRESAS }\end{array}$ SEBRAE. Plantas de Biogás em Operação. [S.I.], agosto de 2020. Disponível em: https://paineislai.sebrae.com.br/single/?appid $=\mathrm{bc} 75184 \mathrm{c}-943 \mathrm{f}-4156-\mathrm{bc} 85$ 305915943ebd\&sheet=fb74886d-b41f-40a1a4df485782d9fda7\&opt=currsel\%2Cctxmenu \&select=clearall. Acesso em: 18 fev. 2021.

VELOSO, A. V.; CAMPOS, A. T.; MARIN, D. B.; MATTIOLI, M. C.; SANTANA, L. C. Custo energético de construção de biodigestores para o manejo e tratamento de resíduos da suinocultura. Engenharia Agrícola, Botucatu, vol. 33, n.4, p. 330-337, outubro-dezembro, 2018.

VIANA, A. P. Q.; SENNA, G. M.; TEIXEIRA, J. V. S.; MONTEIRO, L. A.; PÊGO, K. A. C.; PEREIRA, A. F. Inventário do Ciclo de Vida de um biodigestor: uma perspectiva quantitativa para Design Sistêmico no território do Serro/MG. In: IX Encontro de Sustentabilidade em Projeto. Anais ENSUS 2021 - Design. Florianópolis: Universidade Federal de Santa Catarina, 2021. v. 8. p. 499510.

\section{AGRADECIMENTOS}

Agradecimentos ao Conselho Nacional de Desenvolvimento Científico e Tecnológico (CNPq), à Fundação de Amparo à Pesquisa do Estado de Minas Gerais (FAPEMIG), à Coordenação de Aperfeiçoamento de Pessoal de Nível Superior (CAPES), à Universidade do Estado de Minas Gerais e à Universidade Federal de Minas Gerais, que permitiram a realização desta pesquisa. 